\title{
High-Efficiency Amorphous Silicon Solar Cell on a Periodic Nanocone Back Reflector
}

\author{
Ching-Mei Hsu, Corsin Battaglia,* Celine Pahud, Zhichao Ruan, Franz-Josef Haug, \\ Shanhui Fan, Christophe Ballif, and Yi Cui*
}

Thin-film silicon solar cells, including hydrogenated amorphous silicon (a-Si:H) single-junction and amorphous/microcrystalline silicon (a-Si:H/ $\mathrm{cc}-\mathrm{Si}: \mathrm{H})$ tandem-junction solar cells, are promising candidates for the global terawatt-scale deployment of photovoltaics thanks to the abundance and non-toxicity of their raw materials, and mature fabrication processes. ${ }^{[1,2]}$ Compared to their traditional wafer-based crystalline counterparts, thin-film silicon technologies, with typical silicon absorber thicknesses of only a few hundred nanometers, require much less active material, which can be deposited on a variety of low-cost substrates, such as glass, stainless steel, and plastic. Thinner absorber layers not only contribute to cost reduction but are also beneficial in terms of energy-payback time.

However, as light absorption in silicon becomes small near the bandgap, advanced light-trapping schemes must be implemented to achieve high efficiencies with such thin silicon layers. ${ }^{[3,4]}$ According to Yablonovitch's theory, ${ }^{[5]}$ a maximum absorption enhancement of up to $4 n^{2}$ may be reached, where $n$ is the refractive index of the active absorber material. Experimentally, light trapping is realized by introducing scattering at interfaces between neighboring layers that have different refractive indices. In the substrate configuration (or n-i-p configuration, describing the deposition sequence of n-type, intrinsic, and p-type silicon layers onto the substrate), this is achieved by texturing of the back reflector. Thermally roughened silver films, ${ }^{[6-9]}$ silver-covered randomly oriented $\mathrm{SnO}_{2}$ and $\mathrm{ZnO}$ pyramids grown by chemical vapor deposition, ${ }^{[10-13]}$ and silver-covered vertically aligned $\mathrm{ZnO}$ nanorods grown by hydrothermal synthesis ${ }^{[14]}$ have already been successfully used to enhance light absorption in n-i-p solar cells. Naughton et al. ${ }^{[15]}$ fabricated arrays of silver-covered $1.6 \mu \mathrm{m}$-high tapered Si nanopillars and used those as a back reflector for coaxial n-i-p nanopillar solar

Dr. C.-M. Hsu, Prof. Y. Cui

Department of Materials Science and Engineering Durand Building, 496 Lomita Mall

Stanford University

Stanford, CA 94305-4034, USA

E-mail: yi.cui@stanford.edu

Dr. C. Battaglia, Dr. C. Pahud, Dr. F.-J. Haug, Prof. C. Ballif

École Polytechnique Fédérale de Lausanne (EPFL)

Institute of Microengineering (IMT)

Photovoltaics and Thin Film Electronics Laboratory

Rue Breguet 2, 2000 Neuchâtel, Switzerland

E-mail: corsin.battaglia@epfl.ch

Dr. Z. C. Ruan, Prof. S. H. Fan

Department of Electrical Engineering

Stanford University, USA

DOI: 10.1002/aenm.201100514 cells. Also plasmonic back reflectors based on silver nanoparticles have been investigated in the $n-i-p$ configuration. ${ }^{[16,17]}$

An alternative, highly promising strategy is to utilize periodic nanostructured back reflectors (photonic crystal-based designs) to couple incident light into guided modes, propagating in the plane of the absorber. ${ }^{[18-25]}$ By carefully selecting the periodicities, this approach is capable of providing significant enhancement of the optical path length within the thin absorber layer. Theory predicts that grating structures may even surpass the fundamental $4 n^{2}$ limit. ${ }^{[26-28]}$ In the n-i-p configuration, the integration of one-dimensional (1D) gratings was realized experimentally. ${ }^{[29,30]}$ Söderström et al. ${ }^{[31]}$ used 2D sinusoidal square gratings. Similarly, Ferry et al. ${ }^{[32,33]}$ investigated equally sized silver hole and dot arrays arranged in a square lattice fabricated by laser interference lithography and electron beam lithography, respectively, and replicated them by nanoimprint lithography. Sai et al. ${ }^{[34]}$ used anodically textured aluminum covered by silver to fabricate back reflectors with hexagonal dimple patterns. A back reflector with a similar structure fabricated by photolithography was presented by Biswas et al. ${ }^{[35]}$ Using nanosphere lithography, Hsu et al. ${ }^{[36]}$ fabricated hexagonal arrays of nanocones and used them as a back reflector in n-i-p solar cells. ${ }^{[37]}$ Similar work was carried out later by Tu et al. ${ }^{[38]}$

Although such advanced light-trapping schemes successfully lead to the desired gain in short-circuit current density $\left(J_{\text {sc }}\right)$, the conversion efficiency of the solar cell often improves only marginally as the electrical cell properties characterized by the open-circuit voltage $\left(V_{\text {oc }}\right)$ and fill factor $(F F)$ suffer on textured substrates. Consequently, several studies focused on optimizing the morphology of randomly textured substrates to improve light trapping without compromising the electrical performance. ${ }^{[10,13,39-43]}$

In this Communication, we investigate the influence of the morphology of the back reflector on both the optical and electrical cell performance. Periodic arrays of nanostructures fabricated by nanosphere lithography are ideally suited to such a study as they allow the fabrication of features with precisely defined shape. ${ }^{[36,44]}$ Here we focus on three representative feature shapes: vertical nanopillars, convex nanodomes, and concave nanocones. We demonstrate that a careful optimization of the nanocone shape allows us to achieve an electrical cell performance comparable to what we obtain on flat reference samples, while benefiting fully from a powerful light-trapping enhancement, resulting in solar cells with an excellent initial power conversion efficiency of $9.7 \%$.

Figure 1a shows a sketch of the device geometry. A corresponding cross section imaged by scanning electron microscopy (SEM) is shown in Figure 1b. Periodic nanostructured 


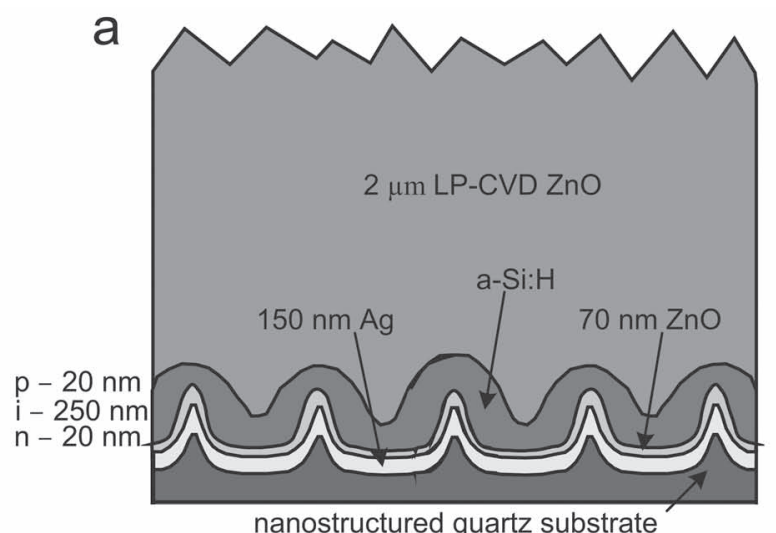

C
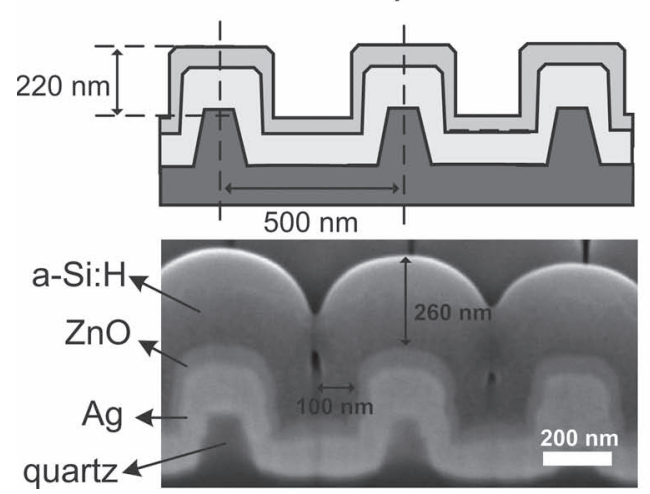

$b$

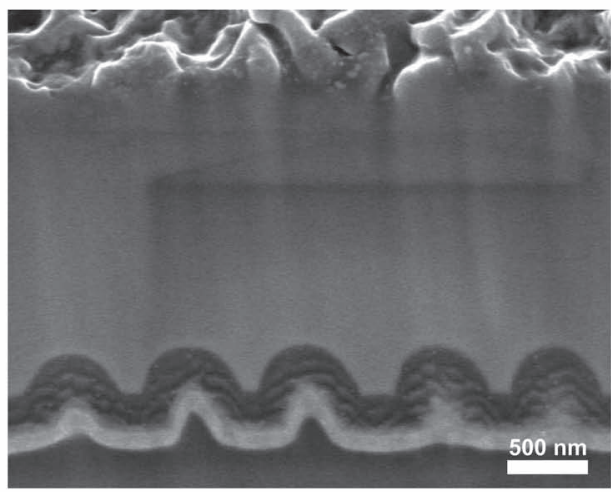

d
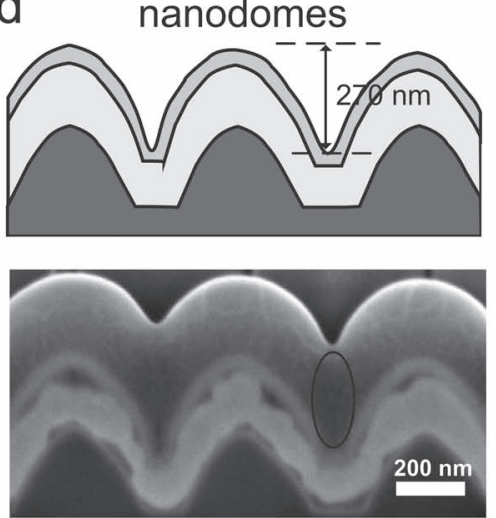

e
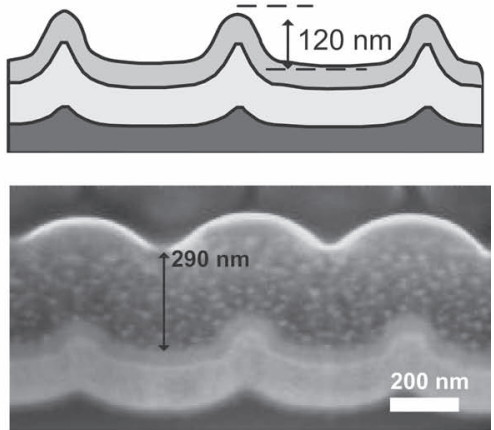

Figure 1. a) Schematic structure of an n-i-p solar cell on a nanostructured substrate and b) a corresponding cross section milled by a focused ion beam and imaged by SEM. c-e) Illustrations of the dimensions and the shapes of nanostructured back reflectors along with SEM cross sections after silicon deposition: c) vertical nanopillars, d) convex nanodomes, and e) concave nanocones.

substrates were fabricated via Langmuir-Blodgett assembly of monodisperse $\mathrm{SiO}_{2}$ nanospheres used as a mask for subsequent reactive ion etching (RIE) of quartz substrates developed and reported previously ${ }^{[36]}$ (for experimental details see the Experimental Section). A $150 \mathrm{~nm}$ thick silver layer was deposited as a back reflector electrode on the nanostructured quartz substrates, followed by a $70 \mathrm{~nm}$ thick $\mathrm{ZnO}$ layer to reduce undesired parasitic absorption of light due to excitations of plasmons in the silver. ${ }^{[45,46]}$ Subsequently, a-Si:H solar cells of size $5 \times 5 \mathrm{~mm}^{2}$ consisting of a stack of $n$-i-p amorphous silicon layers with nominal thicknesses of $20 \mathrm{~nm}, 250 \mathrm{~nm}$, and $20 \mathrm{~nm}$,respectively, were deposited by plasma-enhanced chemical vapor deposition (PE-CVD). ${ }^{[47]}$ Boron-doped $\mathrm{ZnO}$ with a thickness of $2 \mu \mathrm{m}$ was deposited as a front electrode by lowpressure chemical vapor deposition (LP-CVD). ${ }^{[4]}$ Compared to a sputtered front electrode, $\mathrm{ZnO}$ deposited by LP-CVD has the advantage of eliminating problems with sputter-induced damage of the silicon layers and interfaces ${ }^{[49]}$ and provides excellent antireflection properties but also additional light scattering at the air/ZnO interface. ${ }^{[31]}$

To understand the influence of the back reflector morphology on the light-trapping and electrical performance of the solar cell, the three representative morphologies depicted in Figure 1c-e were investigated in the work presented here. Note that the morphology of the substrate was optimized such that the Ag back reflector exhibited the desired characteristic pillar, dome, or cone shape. After silver and $\mathrm{ZnO}$ deposition, the nanopillars and nanodomes had heights of 220 and $270 \mathrm{~nm}$, respectively, whereas the nanocones presented a smoother morphology with a height of $120 \mathrm{~nm}$. These heights were selected to achieve comparable optical cell performance (see below). The pillars exhibit flat tops and vertical side walls. The area between the pillars is flat. The domes have a convex rounded shape. The valleys between the domes are sharp and V-shaped, whereas the valleys between the concave cones are smooth and U-shaped. The reference cell is a planar cell with a flat back reflector.

Figure $2 \mathrm{a}$ presents current density-voltage $(J-V)$ characteristics of the cells on the different back reflector morphologies measured at one-sun illumination (global air mass 1.5 spectrum). $V_{\text {oc }}$ and $F F$ values extracted from these $J-V$ curves are given in Table 1. When comparing the electrical properties, we see that only the nanocone substrate achieves $V_{\text {oc }}$ and $F F$ values comparable to the flat reference cell; $V_{\mathrm{oc}}$ and $F F$ for the nanopillars and nanodomes are substantially deteriorated.

To understand the reduction in $V_{\text {oc }}$ and $F F$ for the nanopillar morphology, we focus on the cell cross section shown in Figure 1c. Careful inspection reveals that the vertical nanopillar morphology leads to pronounced deviations from conformality of the silicon layers: while the total silicon layer thickness on top of the pillar exceeds $250 \mathrm{~nm}$, the thickness on the side walls 
a

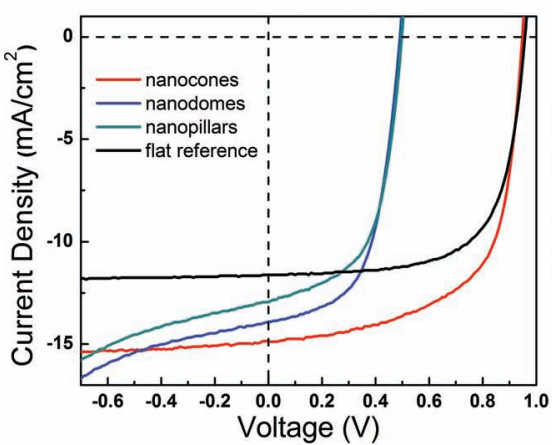

b

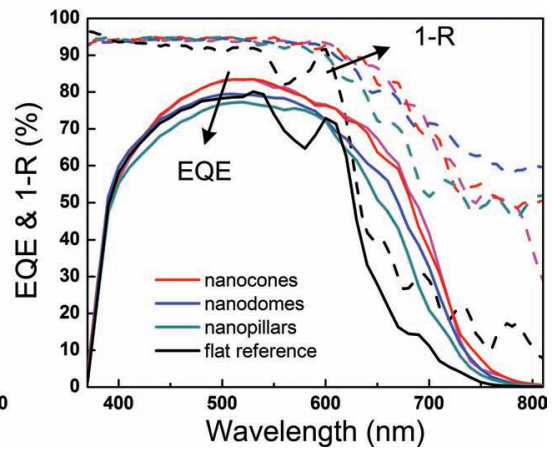

Figure 2. a) Current density-voltage characteristics of the nanostructured cells and the flat reference cell under one-sun illumination. b) External quantum efficiencies and reflectance measurements of the nanostructured cells and the flat reference cell.

of the pillar is only about $100 \mathrm{~nm}$. These thickness variations can be explained by shadowing of the areas at the bottom of the nanopillars by the top of the nanopillars when an almost isotropic distribution of incidence angles of the silicon radicals from the plasma phase is assumed. ${ }^{[50-54]}$ Thickness variations in the intrinsic silicon layer are responsible for local variations in current generation, but more importantly, we must expect that the thin doped layers do not cover the structure sufficiently in areas of steepest slope, causing additional carrier recombination and collection problems, which are reflected in a lower FF.

While non-conformality is not a problem for the convex nanodome morphology, a different kind of problem becomes apparent in Figure 1d. During the deposition of the silicon layers a region of porous, low-density material (marked by an ellipse in Figure 1d) forms in the V-shaped valleys between the domes as the silicon layers growing on neighboring nanodomes collide. Such areas, also called cracks in the literature, were shown to be responsible for a reduction in both $V_{o c}$ and $F F \cdot{ }^{[39,40,55]}$ Note that the fine structure in the silicon layer observed in the SEM images is an artifact arising from ion beam milling and should not be identified with such growth-induced porous regions. In contrast to the nanopillar morphology, no problems with a continuous coverage of the structure by the doped layers are to be expected for the nanodome morphology. However, on the nanodome morphology, we further observe a roughening of the silver back reflector. The roughening most likely occurred during milling by the focused ion beam, as the $\mathrm{ZnO}$ barrier layer still exhibits a perfect dome shape.

Table 1. Summary of performance characteristics for the solar cells on the nanostructured back reflector and the flat reference.

\begin{tabular}{lccccc}
\hline $\begin{array}{l}\text { Morphology (back } \\
\text { electrode) }\end{array}$ & $\begin{array}{c}\text { Period } \\
{[\mathrm{nm}]}\end{array}$ & $\begin{array}{c}V_{\mathrm{oc}} \\
{[\mathrm{mV}]}\end{array}$ & $\begin{array}{c}F F \\
{[\%]}\end{array}$ & $\begin{array}{c}J_{\mathrm{sc}} \\
{\left[\mathrm{mA} \mathrm{cm}^{-2}\right]}\end{array}$ & $\begin{array}{c}\text { Efficiency } \\
{[\%]}\end{array}$ \\
\hline Flat reference & - & 957 & 68.1 & 12.4 & 8.1 \\
Nanopillars & 500 & 554 & 54.9 & 13.0 & 3.9 \\
Nanodomes & 500 & 582 & 58.1 & 14.0 & 4.7 \\
Nanocones & 500 & 947 & 64.5 & 14.9 & 9.1 \\
Nanocones & 350 & 955 & 68.1 & 14.9 & 9.7 \\
\hline
\end{tabular}

The concave nanocone morphology avoids all these problems. Figure 1e confirms the excellent conformality obtained on the nanocones. The total thickness of the silicon layers is $290 \mathrm{~nm}$, as on the flat substrate. Shadowing is not an issue as long as the aspect ratio of the nanocones is relatively low, enabling $V_{\text {oc }}$ and $F F$ values comparable to those of the flat reference (see Table 1).

Despite the lower height of the nanocones compared to the nanopillars and the nanodomes, the nanocone morphology yields the highest short-circuit current. Compared to the flat reference cell, there is a massive gain in $J_{\mathrm{sc}}$ of $2.5 \mathrm{~mA} \mathrm{~cm}{ }^{-2}$ when nanocones are introduced. Although carrier collection problems on the nanopillar and nanodome morphology certainly contribute to the lower $J_{\mathrm{sc}}$, we can see from the reflectance $(R)$ measurements (shown as $1-\mathrm{R}$ in Figure $2 \mathrm{~b}$ ), that all morphologies behave similarly optically up to a wavelength of $600 \mathrm{~nm}$. Between 600 and $700 \mathrm{~nm}$, the nanocone morphology leads to the highest optical absorption (equivalent to lowest reflectance). Between $700 \mathrm{~nm}$ and $800 \mathrm{~nm}$, the nanocones exhibit a slightly higher cell reflectance than the nanodomes, while the nanopillar morphology with its flat pillar tops leads to the highest reflection of light out of the cell above $600 \mathrm{~nm}$.

The external quantum efficiency (EQE) measurements also presented in Figure $2 \mathrm{~b}$ show that most of the current gain realized when nanostructures are introduced is achieved in the long-wavelength range above $600 \mathrm{~nm}$, where the incoming light is coupling to guided modes with the help of the periodic back reflector. ${ }^{[37]}$ The EQEs do not allow a direct comparison of the light-trapping properties of the different morphologies because variations in EQE may be caused by morphology-determined light-scattering properties, morphology-induced changes in the reflectivity of the silver back reflector, ${ }^{[12,38]}$ and carrier-collection losses, expected for both the nanopillar and nanodome morphologies.

Finally, we also investigated the influence of the periodicity on the optical and electrical solar cell performance by reducing the periodicity of the nanocones from $500 \mathrm{~nm}$ to $350 \mathrm{~nm}$. Surprisingly, we only observe minor changes in the EQE (and consequently $J_{\mathrm{sc}}$ ) and reflectance measurements, as shown in Figure 3a (for ease of comparison the data for the nanocones with $500 \mathrm{~nm}$ periodicity and the flat reference are shown again). The insensitivity of the EQE with respect to the period can be qualitatively understood when considering the dense photonic band structure resulting after back-folding of guided mode bands into the first Brillouin zone upon introduction of the hexagonal symmetry. In the $1 \mathrm{D}$ periodic case $\mathrm{e}^{[30]}$ and the 2D square lattice, ${ }^{[33]}$ where back-folding leads to a less dense band structure, relatively sharp dispersing spectral features, identified as excited guided mode resonances, could be clearly distinguished in angle-resolved EQE measurements. For our hexagonal case we do not observe such features. Sai et al. ${ }^{[34]}$ attributed the absence of individual resonances to the insufficient long-range order of their hexagonal back reflector. In our case, where the long-range order is expected to be sufficient, 


\section{a}

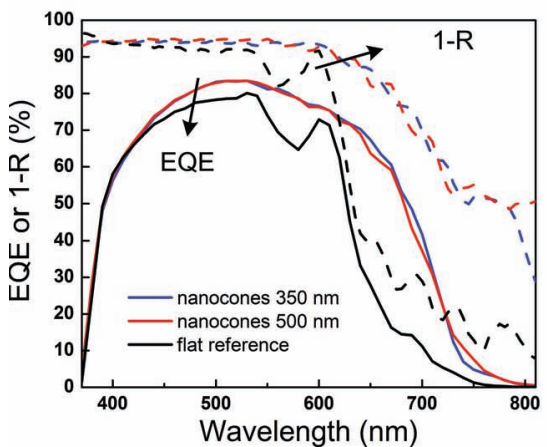

b

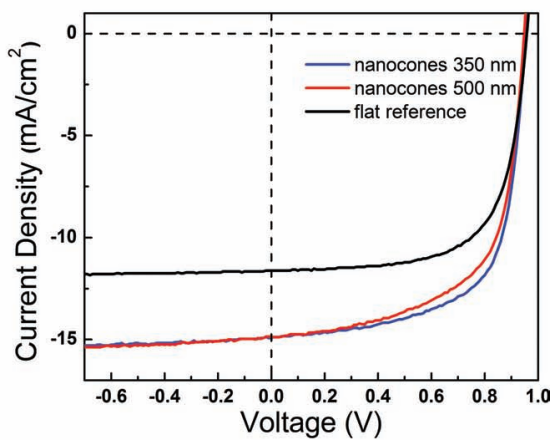

deterioration of $V_{\text {oc }}$ and FF. We demonstrated that the nanocone morphology can maintain simultaneously high $V_{\text {oc }}$ and $F F$ values, while providing excellent $J_{\mathrm{sc}}$ values through efficient light trapping. We also showed that the periodicity of the nanocones does not have a strong influence on $J_{\mathrm{sc}}$, which we explain by the presence of a high density of back-folded guided modes into the first Brillouin zone of the hexagonal lattice. Finally, we presented a nanocone solar cell with an excellent initial efficiency of $9.7 \%$ for an absorber layer thickness of only $250 \mathrm{~nm}$.

Figure 3. a) External quantum efficiencies and reflectance measurements of the nanocone cells with $350 \mathrm{~nm}$ and $500 \mathrm{~nm}$ periodicity and the flat reference cell. b) Current density-voltage characteristics of the nanocone cells with $350 \mathrm{~nm}$ and $500 \mathrm{~nm}$ periodicity and the flat reference cell.

\section{Experimental Section}

the initial randomization of the incoming light at the rough air/ $\mathrm{ZnO}$ interface is likely responsible for exciting guided mode resonances over a broad spectral range of the dense hexagonal band structure, precluding the observation of sharp spectral features.

Although we did not observe any significant changes in the light trapping (and consequently $J_{\mathrm{sc}}$ ) when changing the periodicity, improved $V_{\text {oc }}$ and FF were obtained on the nanocone substrate with $350 \mathrm{~nm}$ periodicity, demonstrating that, within the experimental error bars, values as high as for the flat reference cell may be achieved through careful design of the back reflector. We attribute this improvement in electrical cell performance to a slightly better optimized back reflector morphology for silicon layer deposition. Morphological details of the optimized $350 \mathrm{~nm}$ nanocone substrate are given in the Supporting Information. The improvements in $V_{\mathrm{oc}}$ and $F F$ result in an initial conversion efficiency of $9.7 \%$, to our knowledge the highest efficiency ever achieved for an n-i-p a-Si:H solar cell on a periodic back reflector.

Our case study of the three back reflector morphologies underlines the importance of maintaining high electrical cell performance when maximizing light trapping. Adapting the substrate morphology to achieve both goals is a first important step. Nanosphere lithography is the ideal tool for designing optimized morphologies as it allows for fully independent control over all relevant structural parameters such as feature shape, size, aspect ratio, distance, and periodicity. Furthermore, the nanoimprinting process developed recently by some of us ${ }^{[9,56-58]}$ represents a promising technological bridge to transfer nanocone arrays from academic research to industrial large-area module production as the mechanically robust and chemically inert quartz substrate used to fabricate the nanocone arrays is ideally suited as a master stamp. Future efforts to enhance light trapping in thin-film silicon solar cells should not only focus on substrate morphology but also target a better understanding of the silicon layer deposition regimes in order to further improve material quality and the control over layer conformality. ${ }^{[59]}$

In conclusion, we have investigated the influence of the morphology of nanostructured back reflectors on the optical and electrical performance of n-i-p amorphous silicon solar cells. Both vertical nanopillars and convex nanodomes lead to a

nanospheres were prepared by the modified Stöber process. ${ }^{[00,61]}$ The typical preparation procedure consisted in rapidly mixing two solutions at room temperature. The first solution was a mixture of tetraethyl orthosilicate $(1.3 \mathrm{~mL}, 99.999 \%$ trace metal basis, Sigma-Aldrich) and absolute ethanol (10 mL, 200 proof, USA system). The second solution was a mixture of ammonia $(13 \mathrm{~mL}, 30 \mathrm{wt} \%)$ and absolute ethanol $(10 \mathrm{~mL})$. Under stirring, the second solution was added to the first solution, so that the total volume of the solution was approximately $35 \mathrm{~mL}$. This yielded $500 \mathrm{~nm}$ monodisperse $\mathrm{SiO}_{2}$ nanospheres. The final mixture was stirred for $4 \mathrm{~h}$ to ensure homogeneity, followed by solvent exchange to remove residual precursors ( 3 times ethanol, 2 times distilled water, 2 times ethanol). Surface modification of the as-made nanospheres was achieved by terminating particles with positively charged amine groups. The solution was mixed with distilled water $(1 \mathrm{~mL})$, as-made nanosphere solution $(2 \mathrm{~mL})$, and absolute ethanol $(15 \mathrm{~mL})$. Then aminopropyl methyl-diethoxysilane $(100 \mu \mathrm{L})$ was added while the solution was vigorously stirred. The final solution was stirred overnight and then heated to $100{ }^{\circ} \mathrm{C}$ for $1 \mathrm{~h}$ to strengthen the bonding between the $\mathrm{SiO}_{2}$ surface and the surfactant. The final mixture was cleaned by solvent exchange ( 2 times ethanol, 1 time methanol) and dispersed in methanol for monolayer deposition.

Monolayer Self-Assembly: A Langmuir-Blodgett trough (KSV 2000) was used to fabricate monolayers of nanospheres on 4 inch quartz wafers. The modified $\mathrm{SiO}_{2}$ nanospheres were injected onto the water surface by a syringe pump with an injection rate of $5 \mathrm{~mL} \mathrm{~h}^{-1}$ while the barrier compression rate was controlled at values between 5 and $10 \mathrm{~mm} \mathrm{~min}$. The dipper coater's pulling rate was fixed at $5 \mathrm{~mm} \mathrm{~min}^{-1}$.

Nanostructure Fabrication: Nanostructures were fabricated by RIE (AMT 8100 plasma etcher) using the nanospheres as a mask. The etching is based on fluorine chemistry using a mixture of $\mathrm{O}_{2}$ and $\mathrm{CHF}_{3}$. For the nanocone morphology, the maximal radio-frequency (RF) power and $\mathrm{DC}$ bias were set to $1600 \mathrm{~W}$ and $-530 \mathrm{~V}$, respectively, while the $\mathrm{O}_{2} /$ $\mathrm{CHF}_{3}$ flow rate ratio was maintained between 0.6 and 0.8 . The pressure was kept at 0.8 mTorr during the entire process.

Solar Cell Deposition: After deposition of the sputtered silver and $\mathrm{ZnO}$ back reflector by sputtering, amorphous silicon solar cells were deposited in a PE-CVD reactor operating at $70 \mathrm{MHz}$ with parallel plate configuration at $200{ }^{\circ} \mathrm{C}$. $\mathrm{SiH}_{4}$ and $\mathrm{H}_{2}$ were used as source gases for the intrinsic layer. For doped layers we also used $\mathrm{CH}_{4}$ and $\mathrm{CO}_{2}$. p- and n-type doping were achieved by adding $\mathrm{PH}_{3}$ and $\mathrm{B}\left(\mathrm{CH}_{3}\right)_{3}$, respectively. After cell deposition a $\mathrm{ZnO}$ front contact was deposited by LP-CVD.

Solar Cell Characterization: $V_{\text {oc }}$ and FF were extracted from J-V characteristics measured under a dual lamp sun simulator (Wacom super solar simulator, WXS-220S-L2, AM1.5GMM) under standard test conditions $\left(25^{\circ} \mathrm{C}, 1000 \mathrm{~W} \mathrm{~m}^{-2}\right)$. The short-circuit current density $\left.U_{\mathrm{sc}}\right)$ of the devices was determined in a separate measurement of the EQE after weighting with the global air mass 1.5 spectrum. The structure of the solar cells was characterized by SEM (FEI Strata 235DB dual-beam 
FIB/SEM). The reflectance measurements on the solar cells were carried out with a photospectrometer equipped with an integrating sphere (PerkinElmer Lambda 900).

\section{Supporting Information}

Supporting Information is available from the Wiley Online Library or from the author.

\section{Acknowledgements}

This work is based upon work supported as part of the Center on Nanostructuring for Efficient Energy Conversion (CNEEC) at Stanford University, an Energy Frontier Research Center funded by the US Department of Energy, Office of Science, Office of Basic Energy Sciences under award number DE-SC0001060. A portion of this work is also supported by the US Department of Energy under the award number DE-FG36-08GOI8004 and DE-FG-ER46426. The EPFL team acknowledges the Swiss Federal Energy Office and the Swiss National Science Foundation for funding under project number 101191 and grant number 200021 12577/1

Received: September 1, 2011

Revised: December 5, 2011

Published online: April 13, 2012

[1] A. Shah, P. Torres, R. Tscharner, N. Wyrsch, H. Keppner, Science 1999, 285, 692.

[2] Thin-Film Silicon Solar Cells (Ed: A. Shah), EPFL Press, Lausanne Switzerland 2010.

[3] H. W. Deckman, C. R. Wronski, H. Witzke, E. Yablonovitch, Appl. Phys. Lett. 1983, 42, 968.

[4] T. Tiedje, B. Abeles, J. M. Cebulka, J. Pelz, Appl. Phys. Lett. 1983, 42, 712.

[5] E. Yablonovitch, G. D. Cody, IEEE Trans. Electron Devices 1982, 29, 300.

[6] A. Banerjee, S. Guha, J. Appl. Phys. 1991, 69, 1030.

[7] J. Yang, B. Yan, G. Yue, S. Guha, Mater. Res. Soc. Symp. Proc. 2009, 1153, 1153-A13-02.

[8] J. K. Rath, Y. Liu, M. M. de Jong, J. de Wild, J. A. Schuttauf, M. Brinza, R. E. I. Schropp, Thin Solid Films 2010, 518, e129.

[9] K. Söderström, J. Escarré, O. Cubero, F.-J. Haug, S. Perregaux, C. Ballif, Prog. Photovolt.: Res. Appl. 2011, 19, 202.

[10] T. Matsui, M. Tsukiji, H. Saika, T. Toyama, H. Okamoto, J. Non-Cryst. Solids 2002, 299-302, 1152.

[11] H. Sai, H. Jia, M. Kondo, J. Appl. Phys. 2010, 108, 044505.

[12] K. Söderström, F.-J. Haug, C. Pahud, R. Biron, J. Escarré, M. Duchamp, R. Dunin-Borkowski, C. Ballif, Mater. Res. Soc. Symp. Proc. 2011, 1321, mrss11-1321-a11-05.

[13] K. Söderström, F.-J. Haug, J. Escarré, C. Pahud, R. Biron, C. Ballif, unpublished.

[14] Y. Kuang, K. H. M. van der Werf, Z. S. Houweling, R. E. I. Schropp, Appl. Phys. Lett. 2011, 98, 113111.

[15] M. J. Naughton, K. Kempa, Z. F. Ren, Y. Gao, J. Rybczynski, N. Argenti, W. Gao, Y. Wang, Y. Peng, J. R. Naughton, G. McMahon, M. J. Burns, A. Shepard, M. Clary, C. Ballif, F. J. Haug, T. Söderström, O. Cubero, C. Eminian, Phys. Status Solidi RRL 2010, 4, 181.

[16] E. Moulin, J. Sukmanowski, P. Luo, R. Carius, F. X. Royer, H. Stiebig, J. Non-Cryst. 2008, 354, 2488.

[17] C. Eminian, F.-J. Haug, O. Cubero, X. Niquille, C. Ballif, Prog. Photovolt.: Res. Appl. 2011, 19, 260.

[18] P. Sheng, A. N. Bloch, R. S. Stepleman, Appl. Phys. Lett. 1983, 43, 579.
www.MaterialsViews.com

[19] T. C. Paulick, J. Appl. Phys. 1987, 62, 3016.

[20] C. Heine, R. H. Morf, Appl. Opt. 1995, 34, 2476.

[21] C. Eisele, C. E. Nebel, M. Stutzmann, J. Appl. Phys. 2001, 89, 7722.

[22] N. Senoussaoui, M. Krause, J. Müller, E. Bunte, T. Brammer, H. Stiebig, Thin Solid Films 2004, 451-452, 397.

[23] H. Stiebig, N. Senoussaoui, C. Zahren, C. Haase, J. Müller, Prog. Photovolt.: Res. Appl. 2006, 14, 13.

[24] C. Haase, H. Stiebig, Prog. Photovolt.: Res. Appl. 2006, 14, 629.

[25] O. Isabella, A. Campa, M. C. R. Heijna, W. Soppe, R. van Erven, R. H. Franken, H. Borg, M. Zeman, Proc. 23rd Eur. Photovoltaic Solar Energy Conf. (23rd EU PVSEC) Valencia, Spain, Sept. 2008, DOI: 10.4229/23rdEUPVSEC2008-3AV.1.48.

[26] Z. Yu, A. Raman, S. Fan, Proc. Natl. Acad. Sci. USA 2010, 107, 17491.

[27] Z. Yu, A. Raman, S. Fan, Opt. Express 2010, 18, A366.

[28] F.-J. Haug, K. Söderström, A. Naqavi, C. Ballif, J. Appl. Phys. 2011, 109, 084516.

[29] V. Terrazzoni-Daudrix, J. Guillet, X. Niquille, L. Feitknecht, F. Freitas, P. Winkler, A. Shah, R. Morf, O. Parriaux, D. Fischer, Proc. 3rd World Conf. on Photovoltaic Energy Conversion (Eds: K. Kurokawa, L. Kazmerski, B. McNelis, M. Yamaguchi, C. Wronski, W. C. Sinke), IEEE, Piscataway, USA2003, Vol. 2, p.1596.

[30] K. Söderström, F.-J. Haug, J. Escarré, O. Cubero, C. Ballif, Appl. Phys. Lett. 2010, 96, 213508.

[31] T. Söderström, F.-J. Haug, X. Niquille, C. Ballif, Prog. Photovolt.: Res. Appl. 2009, 17, 165.

[32] V. E. Ferry, M. A. Verschuuren, H. B. T. Li, R. E. I. Schropp, H. A. Atwater, A. Polman, Appl. Phys. Lett. 2009, 95, 183503.

[33] V. E. Ferry, M. A. Verschuuren, H. B. T. Li, E. Verhagen, R. J. Walters, R. E. I. Schropp, H. A. Atwater, A. Polman, Opt. Express 2010, 18, A237.

[34] H. Sai, H. Fujiwara, M. Kondo, Y. Kanamori, Appl. Phys. Lett. 2008, 93, 143501.

[35] R. Biswas, J. Bhattacharya, B. Lewis, N. Chakravarty, V. Dalal, Sol. Energy Mater. Sol. Cells 2010, 2337, 2342.

[36] C.-M. Hsu, S. T. Connor, M. Y. Tang, Y. Cui, Appl. Phys. Lett. 2008 93, 133109.

[37] J. Zhu, C.-M. Hsu, Z. Yu, S. Fan, Y. Cui, Nano Lett. 2010, 10, 1979.

[38] W.-C. Tu, Y.-T. Chang, C.-H. Yang, D.-J. Yeh, C.-I Ho, C.-Y. Hsueh, S.-C. Lee, Appl. Phys. Lett. 2010, 97, 193109.

[39] H. Sakai, T. Yoshida, T. Hama, Y. Ichikawa, Jpn. J. Appl. Phys. 1990, 29, 630.

[40] Y. Nasumo, M. Kondo, A. Matsuda, Jpn. J. Appl. Phys. 2001, 40, L303.

[41] T. Söderström, F.-J. Haug, V. Terrazzoni-Daudrix, C. Ballif, J. Appl. Phys. 2008, 103, 114509.

[42] H. B. T. Li, K. H. M. van der Werf, J. K. Rath, R. E. I. Schropp, Thin Solid Films 2009, 517, 3476.

[43] H. Sai, Y. Kanamori, M. Kondo, Appl. Phys. Lett. 2011, 98, 113502.

[44] H. W. Deckman, J. H. Dunsmuir, Appl. Phys. Lett. 1982, 41, 377.

[45] C. Kothandaraman, T. Tonon, C. Huang, A. E. Delahoy, Mater. Res. Soc. Symp. Proc. 1991, 219, 475.

[46] F.-J. Haug, T. Söderström, O. Cubero, V. Terrazzoni-Daudrix, C. Ballif, J. Appl. Phys. 2009, 106, 044502.

[47] R. Biron, C. Pahud, K. Söderström, J. Escarré, F.-J. Haug, C. Ballif, unpublished.

[48] S. Faÿ, J. Steinhauser, N. Oliveira, E. Vallat-Sauvain, C. Ballif, Thin Solid Films 2007, 515, 8558

[49] Q. H. Fan, M. Deng, Y. Liao, X. Deng, J. Appl. Phys. 2009, 105, 033304.

[50] I. A. Blech, V. A. Vander Plas, J. Appl. Phys. 1983, 54, 3489.

[51] R. C. Ross, J. L. Vossen, Appl. Phys. Lett. 1984, 45, 239.

[52] C. C. Tsai, J. C. Knights, G. Chang, B. Wacker, J. Appl. Phys. 1986, 59, 2998

[53] J. A. Thornton, J. Vac. Sci. Technol. A 1986, 4, 3059. 
[54] A. Nuruddin, J. R. Doyle, J. R. Abelson, Mater. Res. Soc. Symp. Proc. 1992, 258, 33.

[55] M. Python, O. Madani, D. Dominé, F. Meillaud, E. Vallat-Sauvain, C. Ballif, Sol. Energy Mater. Sol. Cells 2009, 93, 1714.

[56] J. Escarré, K. Söderström, F.-J. Haug, C. Battaglia, C. Ballif, Sol. Energy Mater. Sol. Cells 2011, 95, 881.

[57] C. Battaglia, K. Söderström, J. Escarré, F.-J. Haug, D. Dominé, P. Cuony, M. Boccard, G. Bugnon, C. Denizot, M. Despeisse, A. Feltrin, C. Ballif, Appl. Phys. Lett. 2010, 96, 213504
[58] C. Battaglia, J. Escarré, K. Söderström, L. Erni, L. Ding, G. Bugnon, A. Billet, M. Boccard, L. Barraud, S. De Wolf, F.-J. Haug, M. Despeisse, C. Ballif, Nano Lett. 2011, 11, 661.

[59] M. Despeisse, C. Battaglia, M. Boccard, G. Bugnon, M. Charrière, P. Cuony, S. Hänni, L. Löfgren, F. Meillaud, G. Parascandolo, T. Söderström, C. Ballif, Phys. Status Solidi A 2011, 208, 1863.

[60] W. Stöber, A. Fink, E. Bohn, J. Colloid Interface Sci. 1968, 26, 62.

[61] G. H. Bogush, M. A. Tracy, C. F. Zukoski IV, J. Non-Cryst. Solids 1988, 104, 95. 